\title{
Peripapillary retinal nerve fiber layer and choroidal thickness in cirrhosis patients
}

\author{
Espessura da camada de fibras nervosas peripapilares da retina e \\ coroide em pacientes com cirrose
}

\author{
M.Orcun Akdemir ${ }^{1}$, Orhan Ayar ${ }^{1}$, Serpil Yazgan', Sevil Uygun Ilikhan², Erkan Celik¹, Suat H.Ugurbas', Yucel Ustundag ${ }^{3}$
}

\begin{abstract}
Purpose: To evaluate the effect of cirrhosis on peripapillary retinal nerve fiber layer and choroidal thickness with enhanced depth imaging optical coherence tomography. Methods: This cross sectional, single center study was undertaken at Bulent Ecevit University Ophthalmology department with the participation of internal medicine, Gastroenterology department. Patients who were treated with the diagnosis of cirrhosis $(n=75)$ were examined in the ophthalmology clinic. Age and sex matched patients $(n=50)$ who were healthy and met the inclusion, exclusion criteria were included in the study. Complete ophthalmological examination included visual acuity with Snellen chart, intraocular pressure measurement with applanation tonometry, biomicroscopy of anterior and posterior segments, gonioscopy, axial length measurement, visual field examination, peripapillary retinal nerve fiber layer, central macular and subfoveal choroidal thickness measurements. Results: The difference between intraocular pressure values was not statistically significant between cirrhosis and control group $(p=0.843)$. However, mean peripapillary retinal nerve fiber layer thickness was significantly thinner in cirrhosis group in all regions $(p<0.001)$ and subfoveal choroidal thickness was significantly thinner in cirrhosis group also $(p<0.001)$. Moreover, central macular thickness of cirrhosis group was significantly thicker than the control group ( $p=0.001)$. Conclusion: Peripapillary retinal nerve fiber layer and subfoveal choroidal thickness was significantly thinner in cirrhosis patients.
\end{abstract}

Keywords: Cirrhosis; Peripapillary retinal nerve fiber layer; OCT; Subfoveal choroidal thickness

\section{ReSUMO}

Objetivo: Avaliar o efeito da cirrose na camada de fibras nervosas da retina e na espessura da coroide através da tomografia de coerência óptica com imagem de profundidade aprimorada. Métodos: Este estudo transversal, de único centro, foi realizado no departamento de Oftalmologia da Universidade Bulent Ecevit com a participação do departamento de medicina interna em gtastroenterologia. Os pacientes que foram tratados com o diagnóstico de cirrose $(\mathrm{n}=75)$ foram examinados na clínica da oftalmologia. Foram incluídos pacientes correspondentes em idade e sexo $(n=50)$ que fossem saudáveis e possuíssem o critério de inclusão exigido pelo estudo. Realização de exame oftalmológico completo: acuidade visual com tabela de Snellen, a medida da pressão intraocular com tonometria de aplanação, biomicroscopia do segmento anterior e posterior, gonioscopia, medida do comprimento axial, exame de campo visual, camada de fibras nervosas da retina, macular central e medidas de espessura de coroide. Resultados: A diferença entre os valores de pressão intraocular não foram estatisticamente significativos entre os grupos cirrótico e controle $(\mathrm{p}=0,843)$. Entretanto, a espessura da camada de fibras nervosas da retina foi significativamente mais fina no grupo cirrótico em todas as regiões $(\mathrm{p}=0,001)$ e a espessura subfoveal da coroide também foi significativamente mais fina no grupo cirrótico $(\mathrm{p}=0,001)$. Além disso, a espessura macular central do grupo cirrótico foi significativamente mais grossa do que no grupo de controle $(\mathrm{p}=0,001)$. Conclusão: Por fim, as espessuras das camadas de fibras nervosas da retina e subfoveal da coroide foram significativamente mais finas nos pacientes com cirrose.

Descritores: Cirrose; Camada de fibras nervosas da retina; OCT; Espessura de coroide

1,2,3 School of Medicine, Bulent Ecevit University - Zonguldak, Turkey.

There was no public or private financial support.

The authors declare no conflicts of interests.

Received for publication 22/05/2015 - Accepted for publication 05/07/2015

Rev Bras Oftalmol. 2015; 74 (6): 345-9 


\section{INTRODUCTION}

C irrhosis is a chronic liver disease that impairs the function of the liver by causing fibrosis of the tissue. Cirrhosis mainly occurs in patients with chronic liver diseases such as Hepatitis B-virus (HBV), Hepatitis C-virus (HCV) infection, alcoholic liver disease, non- alcoholic fatty liver disease, biliary diseases and autoimmune hepatitis. In addition, anything that damages the liver can cause cirrhosis. Model for End-Stage Liver Disease (MELD) and child classification are most commonly used scales to classify the cirrhosis patients ${ }^{(1-3)}$.

Cirrhosis can be diagnosed by either histological evaluation of the liver biopsy samples and/or by using physical examination, blood tests and radiological findings. However, there is no cure for cirrhosis of the liver. The treatments are based on slowing down liver damage and reducing complications. The treatment options mainly vary with the stage of the illness and in part, depends on the cause of cirrhosis of the liver ${ }^{(4)}$. Currently, the antiviral medications approved by the U.S. Food and Drug Administration (FDA) including interferon alpha, pegylated interferon, lamivudine, adefovir, entecavir, telbivudine, tenofovir, ribavirin, boceprevir, telaprevir, simeprevir, sofosbuvir are used for treatment of HBV and HCV infections ${ }^{(5,6)}$. Furthermore, lifestyle modification, metformin, pioglitazone, ursodeoxycholic acid, statins and prebiotics are the therapeutic options in patients with non-alcoholic steatohepatitis (NASH) and cryptogenic hepatitis ${ }^{(7)}$.

Although cirrhosis is the primary disease of liver, the systemic disorders due to cirrhosis such as hepatic encephalopathy, renal failure, immune suppression, coagulation disorders occur during disease progression and these systemic disorders may eventually lead to death. Eye is the one of the organs that may be affected by the disease. However, effects of cirrhosis on eye have not been evaluated sufficiently ${ }^{(8)}$.

Ocular manifestations of $\mathrm{HCV}$ and $\mathrm{HBV}$ infections are dry eye, Mooren ulcer and retinopathy. In a recent study it was found that chronic $\mathrm{HCV}$ infection causes increased flare in anterior chamber and increased choroidal thickness ${ }^{(8,9)}$. Choroid is vitally important for the function of the retina. In the past, imaging techniques such as indocyanine green angiography, ultrasonography were used and gave limited information about the choroid. However, with the advancement of the spectral domain optical coherence tomography (OCT) and enhanced depth imaging (EDI) which was first described by Spaide, in vitro visualization of choroid resulted in understanding pathologic processes. OCT uses interferometry and low coherence light for high resolution cross section of the posterior segment tissues and it has the advantage of absolute measurement of nerve fiber layer thickness ${ }^{(10)}$.

Aim of the present study is to evaluate the peripapillary retinal nerve fiber layer (RNFL) and choroid findings of cirrhosis patients with EDI-OCT.

\section{Methods}

A cross sectional study was undertaken at Bulent Ecevit University Ophthalmology department with the participation of internal medicine, Gastroenterology department. Patients who were treated with the diagnosis of cirrhosis associated with $\mathrm{HCV}$, HBV infection, non- alcoholic steatohepatitis (NASH) and also cryptogenic cirrhosis $(n=75)$ were examined in the ophthalmology clinic. Age and sex matched patients $(n=50)$ who were healthy and met the inclusion, exclusion criteria were included in the study. Informed consent was obtained from each participant and the study was conducted with the Declaration of Helsinki. The study was approved by Clinical Research Ethics Committee of the Bulent Ecevit University.

A detailed medical history was recorded and complete ophthalmological examinations including visual acuity with Snellen chart, intraocular pressure (IOP) measurement with applanation tonometry, biomicroscopy of anterior and posterior segments, gonioscopy, axial length measurement, visual field examination and peripapillary retinal nerve fiber analysis, central macular thickness and choroidal thickness measurements were done. Retinal analysis by EDI-OCT (Heidelberg Engineering, Heidelberg, Germany) were done after 30-40 minutes pupillary dilation by tropicamide $1 \%$. All patients were evaluated at the same time period to eliminate the effects of diurnal variations of IOP and choroidal thickness. Visual acuity results were transformed to $\log$ MAR for statistical analysis.

Patients who had previous ophthalmic surgery, any ophthalmic disease preventing the view of the anterior chamber, posterior segment detail and retina analysis, glaucoma, pseudoexfoliation, senile macular degeneration, history of central serous chorioretinopathy, uveitis, axial length shorter than $22 \mathrm{~mm}$ and longer than $24 \mathrm{~mm}$, systemic disease other than cirrhosis, auto immune hepatitis, Wilson's disease and alcoholic hepatitis were not included in the study.

Retinal nerve fiber analyze was done automatically in glaucoma mode of the EDI-OCT. A scan circle with a diameter of $3.45 \mathrm{~mm}$ was positioned manually at the center of the optic disc. The mean of hundred images was automatically analyzed by the OCT and measurements used for analysis included global as well as 6 regional subfields (nasal, nasoinferior, nasosuperior, temporal, temporoinferior and temporosuperior).

Macular thickness measurement was done automatically in retina mode, with horizontal scanning of 30x15 degree field. All scans were done in G-Dens mode which includes 37 B-scan images and with eye tracking mode on. Subfoveal choroidal thickness was measured manually. Images were taken in EDI mode, eye tracking on, which scans 30 degrees field and take 100 images. The best image was prepared by the EDI-OCT automatically. Subfoveal choroidal thickness was measured vertically from the outer border of the retinal pigment epithelium (RPE) to the choroidal-scleral interface after the image diameter was increased by $400 \%$. All patients' choroidal thickness measurements were done by 2 experienced ophthalmologist. If any disparity between the measurements occurs, mean of the 2 measurements was included in the statistical analysis (figure 1).

Cirrhosis was diagnosed either by histological evaluation of the liver biopsy samples and/or by using physical examination, blood tests and radiological findings. Besides, the cirrhosis patients were taking the available treatment in accordance with the occurrence of decompensation, characterized by ascites, spontaneous bacterial peritonitis, hepatic encephalo-pathy, or variceal bleeding from portal hypertension. The patients with cirrhosis caused by HBV, HCV and NASH were using some of the drugs including pegylated interferon, lamivudine, entecavir, tenofovir, ribavirin, boceprevir, telaprevir and ursodeoxycholic acid.

SPSS 19.0 used for statistical analysis. Continuous variables are given with mean, standard deviation; qualitative variables 
are given with frequency and percent. Shapiro Wilk test set for test of normality. Kruskal Wallis test for 3+ group comparisons and Mann Whitney U test and Bonferonni corrected Mann Whitney U tests used for 2 group comparisons for non-normal data. Pearson chi-square test used for crosstab comparisons. Spearman correlation analysis used to compare continuous variables. For all statistical comparisons with $\mathrm{p}$ value below 0.05 assumed as there is a statistically significant difference.

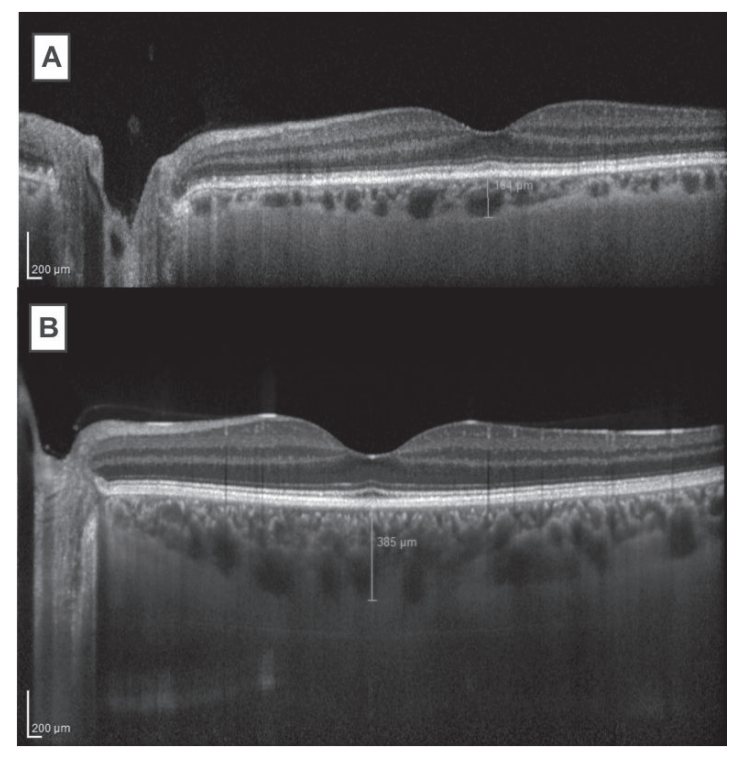

Figure 1: A) Enhanced depth imaging optical coherence tomography of a patient with cirrhosis; B) Enhanced depth imaging optical coherence tomography of a control subject

\section{ResUlTS}

There is no statistically significant difference between the ages and genders of cirrhosis and control groups $(\mathrm{p}=0.753$, $\mathrm{p}=0.470)$ (table 1).

Table 1

Patient characteristics

\begin{tabular}{cccc}
\hline & Cirrhosis n=75 & Control n=50 & p-value \\
\hline Age, Mean \pm SE & $58.2 \pm 11.0$ & $59.3 \pm 10.9$ & 0.753 \\
Female & $38(49.3)$ & $23(46)$ & \\
Gender $(\mathrm{n} \%)$ & & & 0.470 \\
Male & $37(50.7)$ & $27(54)$ & \\
\hline
\end{tabular}

In the cirrhosis group 150 eyes and in the control group 100 eyes were included in the statistical analysis. In cirrhosis group 37 patients were diagnosed as HBV, 18 patients were diagnosed as $\mathrm{HCV}, 10$ patients were diagnosed as non-alcoholic steatohepatitis (NASH), 10 patients were diagnosed as cryptogenic cirrhosis. The patients diagnosed as other than HBV and HCV were regrouped as non-infectious cirrhosis (NIC). Thus, cirrhosis group was sub-grouped as HBV, HCV and NIC.

Mean IOP was $13.9 \pm 3.0 \mathrm{mmHg}$ in cirrhosis group and 14.1 $\pm 2.7 \mathrm{mmHg}$ in control group. The difference between IOP was not statistically significant between cirrhosis and control group ( $\mathrm{p}=0.843$ ). However, mean peripapillary RNFL thickness was significantly thinner in cirrhosis group in all sectors and subfoveal choroidal thickness was significantly thinner in cirrhosis group also. Moreover, central macular thickness of cirrhosis group was significantly thicker than the control group (table 2).

Table 2

Intraocular pressure and retina nerve fiber layer thickness values of groups

\begin{tabular}{lccccccccccc}
\hline & $\begin{array}{c}\text { IOP } \\
(\mathrm{mmHg})\end{array}$ & $\begin{array}{c}\text { RNFL-G } \\
(\mu \mathrm{m})\end{array}$ & $\begin{array}{c}\text { RNFL-N } \\
(\mu \mathrm{m})\end{array}$ & $\begin{array}{c}\text { RNFL-NI } \\
(\mu \mathrm{m})\end{array}$ & $\begin{array}{c}\text { RNFL-NS } \\
(\mu \mathrm{m})\end{array}$ & $\begin{array}{c}\text { RNFL-T } \\
(\mu \mathrm{m})\end{array}$ & $\begin{array}{c}\text { RNFL-TI } \\
(\mu \mathrm{m})\end{array}$ & $\begin{array}{c}\text { RNFL-TS } \\
(\mu \mathrm{m})\end{array}$ & $\begin{array}{c}\text { SFCT } \\
(\mu \mathrm{m})\end{array}$ & $\begin{array}{c}\text { CMT } \\
(\mu \mathrm{m})\end{array}$ \\
\hline $\begin{array}{l}\text { Control } \\
\text { Group } \\
(\mathrm{n}=100)\end{array}$ & $14.1 \pm 2.7$ & $102.9 \pm 8.8$ & $79.3 \pm 11.1$ & $118.0 \pm 19.3$ & $111.1 \pm 18.3$ & $69.9 \pm 9.0$ & $154.1 \pm 20.2$ & $140.0 \pm 18.1$ & $313.3 \pm 57.1$ & $222.0 \pm 19.4$ \\
$\begin{array}{c}\text { Cirrhosis } \\
(\mathrm{n}=150)\end{array}$ & $13.9 \pm 3.0$ & $93.3 \pm 13.3$ & $71.6 \pm 15.8$ & $112.8 \pm 27.3$ & $100.4 \pm 22.9$ & $66.2 \pm 13.3$ & $132.2 \pm 26.1$ & $123.6 \pm 24.4$ & $256.6 \pm 53.7$ & $270.4 \pm 24.8$ \\
p-value & 0.843 & $<0.001$ & $<0.001$ & $<0.001$ & $<0.001$ & $<0.001$ & $<0.001$ & $<0.001$ & $<0.001$ & $<0.001$ \\
\hline
\end{tabular}

IOP - Intraocular pressure; RNFL - Retina nerve fiber layer thickness; G - Global; N- Nasal; NI - Nasoinferior; NS - Nasosuperior;T- Temporal; TI - Temporoinferior; TS - Temporosuperior; S Subfoveal choroidal thickness

There was a statistically significant IOP difference in HBV, HCV and NIC groups $(14.8 \mathrm{mmHg}, 13.3 \mathrm{mmHg}$ and $14.9 \mathrm{mmHg}$ respectively, $\mathrm{p}=0.01)$. In HBV group IOP was higher than the other groups. There was no statistically significant difference between HCV and NIC groups. In spite of the difference between IOP values between groups, there was no statistically significant difference in peripapillary RNFL values between subgroups of cirrhosis patients (table 3).

Moreover, subfoveal macular thickness was significantly thinner in HBV and HCV groups than NIC group (251.3 $\pm 50.8 \mu \mathrm{m}, 246.9 \pm 56.1 \mu \mathrm{m}, 275 \pm 53.4 \mu \mathrm{m}$ respectively, $\mathrm{p}=0.043$ ). There was no correlation between peripapillary RNFL, subfoveal choroidal thickness, central macular thickness and Child, MILD scorings of cirrhosis patients.

\section{DisCUSSION}

This is the first study that reports the effects of cirrhosis on peripapillary RNFL and subfoveal choroid thickness as far as we know. Cirrhosis patients had significantly thin RNFL in all segments of the optic nerve and subfoveal choroidal thickness $(\mathrm{p}<0.001)$. Moreover the mean difference between IOP values in both groups was not statistically significant $(\mathrm{p}=0.843)$. As a result, we could not explain the changes in the optic nerve RNFL with IOP. The RNFL changes may be result of vascular effects of the cirrhosis. There was no correlation between MELD and Child score with the IOP, RNFL or choroidal thickness $(\mathrm{p}=0.848$, $\mathrm{p}=0.870($ RNFL- $\mathrm{G}), \mathrm{p}=0.574)$. 
Table 3

Intraocular pressure and retina nerve fiber layer thickness values in the subgroups of cirrhosis patients

\begin{tabular}{lccccccccc}
\hline & $\begin{array}{c}\text { IOP } \\
(\mathrm{mmHg})\end{array}$ & $\begin{array}{c}\text { RNFL-G } \\
(\mu \mathrm{m})\end{array}$ & $\begin{array}{c}\text { RNFL-N } \\
(\mu \mathrm{m})\end{array}$ & $\begin{array}{c}\text { RNFL-NI } \\
(\mu \mathrm{m})\end{array}$ & $\begin{array}{c}\text { RNFL-NS } \\
(\mu \mathrm{m})\end{array}$ & $\begin{array}{c}\text { RNFL-T } \\
(\mu \mathrm{m})\end{array}$ & $\begin{array}{c}\text { RNFL-TI } \\
(\mu \mathrm{m})\end{array}$ & $\begin{array}{c}\text { RNFL-TS } \\
(\mu \mathrm{m})\end{array}$ & $\begin{array}{c}\text { SFCT } \\
(\mu \mathrm{m})\end{array}$ \\
\hline HBV & $14.8 \pm 2.6$ & $93.8 \pm 12.7$ & $72.1 \pm 15.5$ & $113.9 \pm 29.0$ & $100.7 \pm 24.9$ & $67.9 \pm 12.7$ & $131.0 \pm 25.0$ & $123.5 \pm 24.2$ & $251.3 \pm 50.8$ \\
HCV & $13.3 \pm 3.5$ & $93.5 \pm 12.3$ & $70.3 \pm 15.1$ & $111.7 \pm 25.1$ & $101.3 \pm 20.1$ & $65.8 \pm 12.4$ & $133.9 \pm 25.3$ & $126.8 \pm 27.2$ & $246.9 \pm 56.1$ \\
NIC & $12.8 \pm 2.6$ & $92.1 \pm 15.3$ & $71.9 \pm 17.3$ & $111.9 \pm 26.7$ & $99.0 \pm 22,0$ & $63.6 \pm 14.9$ & $132.8 \pm 29.1$ & $121.0 \pm 22.2$ & $275.1 \pm 53.4$ \\
p-value & 0.001 & 0.957 & 0.269 & 0.746 & 0.955 & 0.401 & 0.643 & 0.414 & 0.043 \\
\hline
\end{tabular}

IOP -Intraocular pressure; RNFL- Retina nerve fiber layer thickness; G - Global; N - Nasal; NI - Nasoinferior; NS - Nasosuperior; T - Temporal; TI - Temporoinferior; TS - Temporosuperior; SFCT - Subfoveal choroidal thickness

Cirrhosis is a very important disease in the developing world. The response of the cells in liver to necrosis is collapse of hepatic lobules, formation of diffuse fibrous septa and nodular regrowth of liver cells. Histologic pattern of cirrhosis is nearly same in all diseases. There are many etiological factors causing cirrhosis. HBV, HCV and alcoholic cirrhosis are main causes of cirrhosis in developed world, $\mathrm{HBV}$ and $\mathrm{HCV}$ are main causes of cirrhosis in developing countries ${ }^{(11)}$.

Cirrhosis can affect extra hepatic systems such as small vessels, kidneys, skin and eyes ${ }^{(12)}$. There are several reports that support the relationship between dry eye and HCV-HBV infection ${ }^{(13,14)}$. Moreover Mooren's ulcer, small vessel vasculitis causing necrotizing scleritis and peripheral keratopathy were reported with $\mathrm{HCV}$ infection ${ }^{(15)}$. $\mathrm{HCV}$ also causes retinopathy characterized by posterior pole retinal hemorrhages, followed by cotton wool spots and peripheral retinal hemorrhages. Retinopathy of HCV is caused by complement mediated immune complexes resulting in vasoocclusion. HBV infection was found to be a risk factor of age related maculopathy ${ }^{(16)}$. Roh et al. found the association between $\mathrm{HBV}$ infection and age related maculopathy after adjusting the multivariate analysis for socioeconomic factors ${ }^{(17)}$. There are some case reports that show the association between liver diseases and eye, such as choroidal and optic nerve infarction, anterior ischemic optic neuropathy, spontaneous expulsive suprachoroidal hemorrhage, and bilateral multifocal central serous retinopathy ${ }^{(18-20)}$.

In a pilot study Strobbe et al. investigated the subfoveal choroidal thickness and aqueous flare in patients with asymptomatic untreated chronic HCV infection. They found that asymptomatic HCV patients had thickened choroids and increased aqueous flare. Mean aqueous flare was significantly higher in HCV patients $(8.37 \pm 2.25 \mathrm{pc} / \mathrm{ms}$ vs $4.56 \pm 1.45 \mathrm{pc} / \mathrm{ms})$. Moreover, they stated that aqueous flare and choroidal thickness increase significantly with liver fibrosis ${ }^{(9)}$. Results of the present study were not consistent with the study done by Strobbe et al. In the present study patients with cirrhosis had thinner choroidal thickness values than control subjects. This difference between the studies was probably because of the stages of the diseases. Our study group includes the cirrhotic patients with $\mathrm{HBV}, \mathrm{HCV}$ and NIC. There was no correlation between CHILD score, MELD score, choroidal thickness and peripapillary RNFL. This makes us think that the metabolic changes in cirrhosis did not affect the RNFL and choroid changes.

In the present study the cirrhosis patients were using different kind of drugs for their treatment but ophthalmic adverse effect like thinning in peripapillary RNFL was not reported in either of the drugs except interferon. There are many studies that report interferon as a cause of retinopathy called interferon associated retinopathy ${ }^{(21)}$. However, only 6 patients of $\mathrm{HCV}$ group was using interferon in the study and there was no interferon associated retinopathy in the study group. All groups were using different kind of drugs but there was no statistically significant difference between the groups in the mean of RNFL thickness. Thus, changes in the peripapillary RNFL and subfoveal choroidal thickness could not be because of the drugs.

There are some various reports investigating the choroidal thickness and glaucoma. Study done by Hirooka et al. found that choroidal thickness in nasal foveal region was thinner in normotension glaucoma. However, they found no difference between choroidal thicknesses in subfoveal and temporal regions (22). These results were not confirmed with other studies ${ }^{(23,24)}$. We cannot conclude that peripapillary RNFL thickness was associated with choroidal thickness. Moreover, because of the decrease in albumin values in cirrhotic patients, it is expected that reduced oncotic pressure in the vessels causes fluid influx to the vessels, and increase the choroidal thickness. We cannot explain the choroidal thickness values with metabolic results of cirrhosis also. As a result, thin RNFL seen in cirrhosis patients is probably because of the vascular effects of cirrhosis. In addition, Manjunath V. et al. reported that there was a weak correlation between central macular thickness and subfoveal choroidal thickness $(r=$ $-0.23, p=0.18)^{(25)}$. Our results were consistent with the study. Direct relationship between retinal thickness and choroidal thickness cannot be resulted with these studies.

\section{ConCLUSION}

In conclusion, peripapillary retina nerve fiber layer thickness thinning may be associated with the microvascular effects of cirrhosis in the absence of increased intraocular pressure. These cirrhotic patients are in active social life. They must be examined routinely to exclude retina nerve fiber layer thickness changes. Because of the systemic nature of the disease, other organs such as eye can be involved and easily overlooked. As far as we know present study is the first study that reports the retina nerve fiber layer thickness and choroid analysis in cirrhosis patients. There is no untreated patient group in the present study and the drugs could not be evaluated separately because of ethical reasons. These seem to be the limitation of the study. Future studies including larger populations are needed to understand the exact mechanism of optic neuropathy and decreased choroidal thickness. 


\section{ACKNOWLEDGEMENTS}

We want to thank Mustafa Cagatay Buyukuysal (department of Biostatistics, School of Medicine, Bulent Ecevit University, Zonguldak, Turkey) for his excellent contribution to the statistical analysis of the study.

\section{REFERENCES}

1. Volarevic V, Nurkovic J, Arsenijevic N, Stojkovic M. Concise review: Therapeutic potential of mesenchymal stem cells for the treatment of acute liver failure and cirrhosis. Stem Cells. 2014;32(11):2818-23

2. Cholongitas E, Papatheodoridis GV, Vangeli M, Terreni N, Patch D, Burroughs AK. Systematic review: The model for end-stage liver disease-should it replace Child-Pugh's classification for assessing prognosis in cirrhosis? Aliment Pharmacol Ther. 2005;22(11-12):1079-89.

3. Kamath PS, Kim WR. Advanced Liver Disease Study Group. The model for end-stage liver disease (MELD). Hepatology. 2007;45(3):797-805.

4. Heidelbaugh JJ, Bruderly M. Cirrhosis and chronic liver failure: part I. Diagnosis and evaluation. Am Fam Physician. 2006;74(5):756-62.

5. Niederau C. Chronic hepatitis B in 2014: Great therapeutic progress, large diagnostic deficit. World J Gastroenterol. 2014;20(33):11595-617.

6. Yau AH, Yoshida EM. Hepatitis C drugs: The end of the pegylated interferon era and the emergence of all-oral interferon-free antiviral regimens: A concise review. Can J Gastroenterol Hepatol. 2014;28(4):445-51.

7. Dietrich P, Hellerbrand C. Non-alcoholic fatty liver disease, obesity and the metabolic syndrome. Best Pract Res Clin Gastroenterol. 2014;28(4): 637-53.

8. Jacobi C, Wenkel H, Jacobi A, Korn K, Cursiefen C, Kruse FE. Hepatitis C and ocular surface disease. Am J Ophthalmol. 2007;144(5):705-11.

9. Strobbe E, Cellini M, Campos EC. Aqueous flare and choroidal thickness in patients with chronic hepatitis $\mathrm{C}$ virus infection: a pilot study. Ophthalmology. 2013;120(11):2258-63.

10. AAO Basic Clinical Science Course. Section 10. Glaucoma. Chapter 3. Clinical evaluation. Washington: American Academy Ophthalmology; 2010-2011. p.33-83.

11. Sherlock S, Dooley J. Diseases of the liver and biliary system. 11th ed. New York-Wiley-Blackwell; 2007.

12. Himoto T, Masaki T. Extrahepatic manifestations and autoantibodies in patients with hepatitis $\mathrm{C}$ virus infection. Clin Dev Immunol. 2012; 871401.
13. Zegans ME, Anninger W, Chapman C, Gordon SR. Ocular manifestations of hepatitis C virus infection. Curr Opin Ophthalmol. 2002;13(6):423-7.

14. Wang $\mathrm{Tj}$, Wang $\mathrm{Ij}, \mathrm{Hu} \mathrm{Cc}$, Lin HC. Comorbidities of dry eye disease: a nationwide population based study. Acta Ophthalmol. 2012;90(7):663-8

15. Wilson Se, Lee Wm, Murakami C, Chawla Y, Dhiman RK. Mooren's type hepatitis c virus associated corneal ulceration. Ophthalmology. 1994;101(4):736-45

16. Abe T, Sakuragi S, Kuramitsu OT. Retinopathy associated with hepatitis C virus. Jpn J Clin Ophthalmol (Rinsho Ganka). 1993;47: 297-300.

17. Roh MI, Kim JH, Byeon SH, Koh HJ, Lee SC, and Kwon OW. Estimated prevalence and risk factor for age related maculopathy. Yonsei Med J. 2008; 49(6): 931-41.

18. O'Neil YK, Jirawuthiworavong GV, Podell DN, Lesser RL. Choroidal and optic nerve infarction in hepatitis c-associated polyarteritis nodosa. J Neuro-Ophthalmol. 2007;27(3):184-8.

19. Knyazer B, Lifshitz T, Marcus M, Kratz A, Zlotnik A, Levy J. Anterior ischemic optic neuropathy in a patient with hepatitis $\mathrm{C}$ treated with interferon-alpha and ribavirin. Isr Med Assoc J. 2011;13(4): 251-3.

20. Gkotsi D, Gupta M, Lascaratos G, Syrogiannis A, Dhillon B. Alcoholic liver disease and bilateral multifocal central serous retinopathy: a case report. J Med Case Rep. 2013;7(1):43.

21. Hayasaka S, Nagaki Y, Matsumoto M, Sato S. Interferon associated retinopathy. Br J Ophthalmol. 1998;82(3): 323-5.

22. Hirooka K, Fujiwara A, Shiragami C, Baba T, Shiraga F. Relationship between progression of visual field damage and choroidal thickness in eyes with normal-tension glaucoma. Clin Exp Ophthalmol. 2012;40(6):576-82.

23. Maul EA, Friedman DS, Chang DS, Boland MV, Ramulu PY, Jampel HD, et al. Choroidal thickness measured by spectral domain optical coherence tomography: factors affecting thickness in glaucoma patients. Ophthalmology. 2011;118(8):1571-9.

24. Mwanza JC, Hochberg JT, Banitt MR, Feuer WJ, Budenz DL. Lack of association between glaucoma and macular choroidal thickness measured with enhanced depth imaging optical coherence tomog raphy. Invest Ophthalmol Vis Sci. 2011;52(6):3430-5.

25. Manjunath V, Taha M, Fujimoto JG, Duker JS. Choroidal thickness in normal eyes measured using Cirrus-HD optical coherence tomography. Am J Ophthalmol. 2010;150(3):325-9.

\section{Corresponding author}

Mehmet Orcun Akdemir, M.D.

Department of Ophthalmology, School of Medicine

Bulent Ecevit University, Kozlu - Zonguldak, Turkey

Tel: 00905053974692 - Fax: 00903722612001

E-mail: doktorcun@yahoo.com 